\title{
SAFETY OF THE METHOTREXATE-LEFLUNOMIDE COMBINATION IN THE BRAZILIAN REGISTRY OF BIOLOGICAL THERAPIES IN RHEUMATIC DISEASES (BIOBADABRASIL)
}

Markus Bredemeier (Grupo Hospitalar Conceição, Porto Alegre, RS, Brasil), lêda Maria Laurindo (Universidade Nove de Julho, São Paulo, SP, Brasil), Marcelo Medeiros Pinheiro (Escola Paulista de Medicina - UNIFESP, São Paulo, SP, Brasil), José Caetano Macieira (Hospital Universitário - Universidade Federal de Sergipe, Aracaju , SE, Brasil), Angela Luiza B P Duarte (Hospital das Clínicas - Universidade Federal de Pernambuco, Recife, PE, Brasil), Adriana Maria Kakehasi (Programa de Pós-graduação em Ciências Aplicadas à Saúde do Adulto - UFMG, Belo Horizonte, MG, Brasil), Barbara Stadler Kahlow (Hospital Evangélico de Curitiba, Curitiba, PR, Brasil), Roberto Ranza (Universidade Federal de Uberlândia , Uberlândia , MG, Brasil), Ana Cristina Medeiros-Ribeiro (Universidade de São Paulo, São Paulo, SP, Brasil), Valeria Valim Cristo (Universidade Federal do Espírito Santo, Vitória, ES, Brasil), Manoel Barros Bertolo (Universidade de Campinas, Campinas, SP, Brasil), José Roberto Silva Miranda

(Artrocenter Clínica Médica, Taubaté, SP, Brasil), Claiton Viegas Brenol (Hospital de Clínicas da Universidade Federal do Rio Grande do Sul, Porto Alegre, RS, Brasil), Glaucio Ricardo Werner Castro (Hospital Governador Celso Ramos, Florianópolis, SC, Brasil), Vander Fernandes (Hospital Geral da Universidade de Cuiabá , Cuiabá, MT, Brasil), David Cesar Titon (Universidade Federal do Paraná, Curitiba , PR, Brasil), Maria de Fátima Lobato C Sauma (Hospital de Clínicas da Universidade Federal do Pará, Belém, PA, Brasil), Ivanio Alves Pereira (Hospital Universitário da Universidade Federal de Santa Catarina , Florianópolis, SC, Brasil), Reginaldo Botelho Teodoro (Hospital da Universidade Federal do Triângulo Mineiro, Uberaba, MG, Brasil), Hellen Mary Silveira Carvalho (Hospital de Base do Distrito Federal , Brasília, DF, Brasil), Andre Luiz Shinji Hayata (Clínica de Reumatologia de Osasco, Osasco, SP, Brasil), Paulo Louzada Jr (Hospital das Clínicas de Ribeirão Preto, Ribeirão Preto , SP, Brasil), Aline Ranzolin (IMIP - Fundação Martiniano Fernandes, Recife, PE, Brasil), Inês Guimarães Silveira (Pontiícfa Universidade Católica - RS, Porto Alegre, RS, Brasil), Sérgio Cândido Kowalski (Hospital de Clínicas da Universidade Federal do Parana, Curitiba, PR, Brasil), Daniel Feldman Pollak ( Universidade Federal de São Paulo - UNIFESP, São Paulo, SP, Brasil), Sâmia A S Studart (Hospital Geral de Fortaleza, Fortaleza, CE, Brasil), Geraldo R C Pinheiro (Hospital Universitário Pedro Ernesto - UERJ, Rio de Janeiro, RJ, Brasil), Washington Alves Bianchi (Santa Casa de Misericórdia, Rio de Janeiro, RJ, Brasil), Roberto Acayaba Toledo (Fundação Faculdade Medicina São José do Rio Preto, São José do Rio Preto, SP, Brasil), Jéssica Martins Amaral (Programa de Pós-graduação em Ciências Aplicadas à Saúde do Adulto - UFMG, Belo Horizonte, MG, Brasil), Laurindo Ferreira Rocha Júnior (Fundação Martiniano Fernandes, Fortaleza, CE, Brasil), Morgana Ohira Gazzeta (Santa Casa de Misericórdia, Rio de Janeiro, RJ, Brasil), Lina Oliveira Carvalho (Hospital Universitário - Universidade Federal de Sergipe, Aracajú, SE, Brasil), José Roberto Provenza (Sociedade Brasileira de Reumatologia, São Paulo, SP, Brasil)

\section{BACKGROUND}

The combination of methotrexate (MTX) with leflunomide (LEF), despite being effective in the therapy of rheumatoid arthritis (RA)[1], has not been widely accepted[2,3]. In spite of evidence that the MTX-LEF combination is generally safe $[1,4,5]$, the relatively small number of patients and treatment courses have not permitted firm conclusions. Our objective was to evaluate the safety of the combination MTX-LEF in Brazilian patients with RA included in BiobadaBrasil.

\section{MATERIALS AND METHODS}

BiobadaBrasil is a multicentric prospective cohort involving patients with rheumatic diseases who started their first biologic or a synthetic disease modifying anti-rheumatic drug (DMARD) [6]. This analysis includes RA (2010 criteria) patients recruited from Jan 2009 to Aug 2018, followed-up for one or multiple courses of treatment until censoring (latest date, September 03, 2018) or occurrence of the outcome of interest. 
The primary outcome was the incidence of any serious AE (SAE). Secondary outcomes were infectious, non-mycobacterial pulmonary infectious, hepatic, hematologic and cardiovascular SAE. Multivariate Cox proportional hazards models (with DMARDs included as time-varying covariates) were used to estimate hazard ratios $(\mathrm{HR})$ and $95 \%$ confidence intervals $(\mathrm{Cl})$; analyses were performed with the Survival package of $R$.

\section{RESULTS}

Sample: 2055 RA patients, female=85.1\%, median disease duration=6.02 yrs; mean (SD) age=50.3 (12.1) yrs; mean (SD) DAS28=5.3 (3.1); seronegative RA=14.1\%; median follow-up duration=3.9 yrs. In total, 565 patients received 664 courses of the MTX-LEF combination (median duration, 2.5 years/course; 2209 person-years). The incidence of SAE was $4.75 / 100$ patient-year in the entire sample. There was no significant increase in the risk of any of the outcomes with the use of combined therapy (table 1) comparing with methotrexate (without leflunomide). The use of antimalarials was associated with reduced risk of $\mathrm{SAE}$ (adjusted $\mathrm{HR}=0.62,95 \% \mathrm{Cl} 0.48$ to $0.79, \mathrm{P}<0.001$ ), while sulfasalazine (adj. $\mathrm{HR}=1.78$, 1.18 to $2.68, P=0.006$ ) and biologic DMARDs/tofacitinib (adj. $H R=1.67,1.31$ to $2.12, P<0.001$ ) increased the risk of SAE.

\section{CONCLUSION}

BIOBADABRASIL results suggest that the combination of methotrexate and leflunomide is safe in the treatment of RA.

REFERENCES:

[1] Ann Intern Med 2002; 137: 726.

[2] Ann Rheum Dis 2010; 69: 43.

[3] Ann Pharma cother 2004; 38: 1206.

[4] J Rheumatol 2013; 40: 228.

[5] Rev Bras Reumatol 2011; 51: 141/51:152. 